patients in contact with services during an index month, as well as selected groups who were not in contact with services in the index month, but had been in the previous 3 years. Also included was a group ascertained through 'marginal' services, such as homeless shelters.

The study established diagnoses, symptoms, disability and service utilisation for each participant. In terms of medication, around half were on 'typical' antipsychotics, with half of these being administered in depot form. A further $8.3 \%$ were on clozapine, $13.3 \%$ on risperidone and $8.8 \%$ on olanzapine. Demographic and illness parameters did not distinguish medication groups, although usage varied across different service providers. Clozapine tended to be used in patients with a long illness duration, compared with other agents.

Patients reported a mean of around 3.5 of a possible 14 medication side-effects. Some $83 \%$ of those using depot medication reported side-effects, compared with $79 \%$ of those using typical oral medication. Patients on depot preparations of typical antipsychotics reported the highest rates of akathisia, and were also least likely to perceive their medication as helpful; indeed, $17 \%$ rated it as 'not helpful' $v .12 \%$ of those on oral typical antipsychotics, $10 \%$ of those on olanzapine/risperidone and $5 \%$ of those on clozapine.

Thus, in unselected patient populations, patient perception of depot medications appears less favourable than the studies reviewed by Walburn et al might lead us to believe. Clinicians should attempt to enhance adherence to antipsychotics by means other than necessarily resorting to depot medication.

Jablensky, A., McGrath, J. J., Herrman, H., et al (2000) Psychotic disorders in urban areas: an overview of the Study on Low Prevalence Disorders. Australian and New Zealand Journal of Psychiatry, 34, 221-236.

Walburn, J., Gray, R., Gournay, K., et al (200I) Systematic review of patient and nurse attitudes to depot antipsychotic medication. British Journal of Psychiatry, I79, 300-307.

D. J. Castle Mental Health Research Institute, 155 Oak Street, Parkville, Victoria 3052, and University of Melbourne, Melbourne, Australia

V. Morgan University Department of Psychiatry, University of Western Australia, Perth, Western Australia

\section{Depot injections and nut allergy}

Many clinicians may be unaware of the use of nut oil as a vehicle within antipsychotic depot preparations. We report a case of possible coconut hypersensitivity which occurred during treatment with flupenthixol decanoate.

An elderly woman with a diagnosis of paranoid schizophrenia was commenced on a 3-weekly depot of flupenthixol decanoate $(20 \mathrm{mg})$. After 5 months (seven injections), she complained of soreness and swelling around the injection site. The depot was subsequently administered at a different site and in a lower volume of oil. Within 1 hour, she experienced intense local irritation and a generalised pruritus. Her systemic symptoms began to resolve within 24 hours, but continued scratching at the injection site led to a localised infection. Since then she has refused further depot medication and is hostile towards psychiatric services. Enquiries revealed that all depot preparations of flupenthixol contain coconut oil.

The symptoms described by the patient might be attributable to a late hypersensitivity reaction to flupenthixol decanoate, but they may also be a manifestation of a previously undiagnosed coconut allergy. The patient has refused to be tested for specific immunoglobulin $\mathrm{E}$ antibodies to coconut and is guarded when questioned about her dietary habits. Although coconut hypersensitivity is relatively rare, coconut allergens show immunological cross-reactivity with both soy and walnut proteins (Teuber \& Peterson, 1999). The prevalence of allergies to peanut and tree nut (e.g. walnut, brazil nut) is increasing (Sicherer et al, 2000). Similarly, the number of reported cases of hypersensitivity to sesame seed and sesame oil has risen in recent years (Levy \& Danon, 2001). In sensitised individuals, non-ingestion exposure to food allergens results in less-severe reactions than are observed following inhalation or ingestion (Sicherer et al, 1999).

Depot preparations consist of an ester of the antipsychotic drug in a solution of coconut oil (flupenthixol, zuclopenthixol) or sesame oil (haloperidol, pipothiazine, fluphenazine). Currently, the British National Formulary (British Medical Association \& Royal Pharmaceutical Society of Great Britain, 2001) provides no information regarding the oils used in depot preparations. Individual drug datasheets can also be misleading: coconut oil is referred to as 'vegetable oil' in the flupenthixol datasheet. Although guidelines regarding the labelling of food products are sometimes seen as overinclusive, they allow consumers to make an informed choice. Depot medications are in widespread use, particularly in patients with a history of non-compliance (Adams et al, 2001). To avoid further alienating such patients from psychiatric services, it is essential that both clinicians and patients are able to make informed treatment decisions. This can only occur if the constituents of depot preparations, particularly those relating to nut and seed products, are more clearly labelled.

\section{Declaration of interest}

S. R. has received support for attendance at conferences from Lilly and Janssen; R. H. has received support for attending conferences from Janssen, Eisai and Pfizer and has been on advisory boards for Janssen, Pfizer and Shire.

Adams, C. E., Fenton, M. K. P., Quraishi, S., et al (200I) Systematic meta-review of depot antipsychotic drugs for people with schizophrenia. British Journal of Psychiatry, 179, 290-299.

British Medical Association \& Royal Pharmaceutical Society of Great Britain (200I) British National Formulary, No. 42 (September issue). London \& Wallingformd: BMJ Books \& Pharmaceutical Press.

Levy, Y. \& Danon, Y. L. (200I) Allergy to sesame seed in infants. Allergy, 56, 193-194.

Sicherer, S. H., Furlong, T. J., DeSimone, J., et al (1999) Self-reported allergic reactions to peanut on commercial airliners. Journal of Allergy and Clinical Immunology, 104, 186-189.

_, Sampson, H. A. \& Burks, A.W. (2000) Peanut and soy allergy: a clinical and therapeutic dilemma. Allergy, 55, 515-52I.

Teuber, S. S. \& Peterson,W. R. (1999) Systemic allergic reaction to coconut (Cocos nucifera) in 2 subjects with hypersensitivity to tree nut and demonstration of cross-reactivity to legumin-like seed storage proteins: new coconut and walnut food allergens. Journal of Allergy and Clinical Immunology, 103, II80-1185.

S. Reeves, R. Howard Section of Old Age Psychiatry, Institute of Psychiatry, De Crespigny Park, Denmark Hill, London SE5 8AF, UK

\section{Stigma, suicide and religion}

A comment by Tadros \& Jolly (2001) that 'Hinduism and Buddhism, among other Eastern religions, have not had a traditionally negative view of suicide' is not totally correct. According to Hinduism, 'The law of action is inexorable and inescapable. It is not bound by the chain of time. If you 